\title{
Prophylaxis of Diphenhydramine on Postoperative Catheter Related Bladder Discomfort in Patients Undergoing Gynecologic Laparoscopic Surgery: A Randomized Double-Blind Clinical Study
}

Yan-Syun Zeng, Ping-Hsun Feng, Chin-Chen Chu, Yu-Yu Li, Ja-Ping Shieh, Jen-Yin Chen

Department of Anesthesiology, Chi Mei Medical Center, Tainan, Taiwan

\section{Study Objective}

To evaluated the effectiveness of diphenhydramine, an antihistamine with anti-muscarinic properties, for prevention of postoperative catheter related bladder discomfort (CRBD).

\section{Design}

Randomized, double-blind control study.

\section{Setting}

Postoperative recovery rooms and gynecological wards of a medical center.

\section{Pateints}

96 ASA physical status I and II adult female patients (20-60 yr) scheduled for elective gynecologic laparoscopic surgery.

\section{Intervention}

Patients were randomized into two groups of 48 patients each. The control $(\mathrm{C})$ group received placebo (normal saline $2 \mathrm{ml}$ ) whereas the diphenhydramine (D) group received diphenhydramine $30 \mathrm{mg}$ intravenously after induction of general anesthesia. Then, all patients were catheterized with a $14 \mathrm{Fr}$ Foley catheter and the balloon was inflated with $10 \mathrm{ml}$ of normal saline.

\section{Measurements}

Bladder discomfort and its severity were assessed at 1,2 and $6 \mathrm{~h}$ postoperatively. The severity of CRBD was graded as none, mild, moderate and severe. Adverse effects of diphenhydramine such as sedation, dry mouth or gastrointestinal upset were recorded.

\section{Main Results}

The incidence of CRBD was lower in the $D$ group compared with the $C$ group at 2 and $6 \mathrm{~h}$ postoperatively $(P<0.05)$. Diphenhydramine treatment also reduced the severity of CRBD at $6 \mathrm{~h}$ postoperatively $(P<0.05)$. There were no significant differences in side effects, such as sedation, dry mouth or gastrointestinal upset between the two groups $(P>0.05)$.

\section{Conclusion}

Prophylactic administration of diphenhydramine $30 \mathrm{mg}$ after induction of general anesthesia reduced the incidence and severity of postoperative bladder discomfort without significant side effects in patients receiving gynecologic laparoscopic surgery.

Table 1. Demographic data, duration of surgery, and analgesic requirement.

\begin{tabular}{|c|c|c|}
\hline & $\begin{array}{l}\text { Control } \\
(\mathrm{N}=46)\end{array}$ & $\begin{array}{l}\text { Diphenhydramine } \\
\quad(N=46)\end{array}$ \\
\hline Age $(y r)$ & $41.02 \pm 7.7$ & $38.93 \pm 8.9$ \\
\hline Height (cm) & $158.59 \pm 5.3$ & $158.39 \pm 4.9$ \\
\hline Weight (kg) & $56.86 \pm 8.6$ & $57.61 \pm 9.9$ \\
\hline Duration of surgery (min) & $89.67 \pm 34.0$ & $92.17 \pm 33.7$ \\
\hline $\begin{array}{l}\text { Post-operative meperidine } \\
\text { requirement (mg) }\end{array}$ & $21.09 \pm 23.4$ & $27.5 \pm 24.7$ \\
\hline $\begin{array}{l}\text { Post-operative ketorolac } \\
\text { requirement }(\mathrm{mg})\end{array}$ & $27.93 \pm 16.0$ & $24.35 \pm 18.3$ \\
\hline
\end{tabular}

Data are presented as mean \pm standard deviation (SD).

No difference between groups.

Table 2. Incidence and severity of bladder discomfort, data presented as number of patients and (percentage).

\begin{tabular}{|c|c|c|c|c|c|c|}
\hline Time (h) & 1 & & & 2 & 6 & 6 \\
\hline Groups & C & $\mathrm{D}$ & C & $\mathrm{D}$ & C & $\mathrm{D}$ \\
\hline $\begin{array}{l}\text { No discomfort, } \\
\text { n (\%) }\end{array}$ & $22(47.8)$ & $27(58.7)$ & $19(41.3)$ & $30(65.2)$ & $20(43.5)$ & $35(76.1)$ \\
\hline Discomfort, n (\%) & $24(52.2)$ & $19(41.3)$ & $27(58.7)$ & $16(34.8)^{*}$ & $26(56.5)$ & $11(23.9)^{*}$ \\
\hline \multicolumn{7}{|c|}{ Severity of bladder discomfort } \\
\hline Mild & $17(36.9)$ & $13(28.26)$ & $23(50.0)$ & $12(26.09)$ & $24(52.17)$ & $10(21.74)^{*}$ \\
\hline Moderate & $6(13.04)$ & $6(13.04)$ & $3(6.52)$ & $3(6.52)$ & $1(2.17)$ & $1(2.17)$ \\
\hline Severe & $1(2.17)$ & $0(0)$ & $1(2.17)$ & $1(2.17)$ & $1(2.17)$ & $0(0)$ \\
\hline
\end{tabular}

